\section{Questionnaires and copyright}

SIR - I agree that there should not have been civil litigation in the case of Dr T.H. Lam (Nature 373, 458 \& 465; 1995).

In 1986, when the dispute arose between Dr Linda Koo and Professor J.H.C. Ho on the one hand and Dr Lam on the other, no formal mechanism existed within the university for the redress of staff grievances. The university, under my predecessor, nevertheless made every possible attempt at conciliation: an ad hoc group, chaired by a pro-vice-chancellor, was set up to enquire into the matter. But Koo and Ho chose to initiate civil court proceedings.

When I arrived at the university as vice-chancellor, I offered to try to reconcile the parties. Because they had initiated court proceedings, I sought advice from the university's solicitors, who advised me that the internal enquiry should be stopped, on the grounds that neither party would want to disclose information that might adversely affect his or her own case. Since then, we have instituted formal procedures, although they are as yet untested.

\section{Wang Gungwu}

University of Hong Kong,

Pokfulam Road, Hong Kong

SIR - I represented Dr Lam both before the Court of Appeal in the case brought by Dr Koo and before the Hong Kong University Committee on Personal Matters, a disciplinary committee of the university, and the question of whether Lam had "copied" any part of Koo's questionnaire was extensively debated.

You correctly state that the University Committee reached opposing conclusions on the facts from Mr Justice Bokhary, who had tried the initial case, and you criticize them for doing so. You state "Hong Kong's Appeal Court confirmed an earlier court decision in favour of $\mathrm{Dr}$ Linda Koo", but there is a legal rule that a court of appeal, provided there is some evidence to justify a judge's factual findings, will not alter them at all (with rare exceptions). Consequently the factual decision in almost all civil cases - which are tried by a judge alone - depends only on one person's judgement. Such a legal system is obviously fallible, but at the moment we do not have a better one.

The important legal issue that Lam's case highlights is how a genuine review can be made in legal appeals of the truth or falsity of the facts found by a court without re-hearing all the evidence in every case. Fortunately for him, in Lam's case the members of the university committee (unlike the court of appeal) had a statutory personal responsibility to decide for themselves what were the facts, so that they could not just accept the findings made by the judge without themselves hearing evidence.

The committee consisted of six distinguished professors. They received far more evidence than was called at the civil trial; this included the two research assistants of the protagonists, who each (contrary to the sworn evidence of $\mathrm{KoO}$ at the trial that she had kept her questionnaire locked away and had shown it to no one else) revealed that each of them at various times had been given a copy of her questionnaire, and that this had also been used in interviewing patients. They point out in their report (contrary to what you state) that Koo and Ho "decided not to appear before the Committee to assist in its investigation...however we did receive two written submissions" from them.

Perhaps more important for the future in this branch of science was the written evidence of some 26 epidemiologists, who had each seen and compared the two questionnaires. The committee in its report quoted one distinguished professor emeritus: "I am absolutely astonished at the claim that one is copied from the other...it is hard to imagine two more dissimilar questionnaires. I found the suggestion that one was copied from the other quite absurd."

The committee went on to say: "Similar views were expressed by the rest - that the questionnaires were quite different, that the Koo questionnaire was inferior to the Lam questionnaire, and that there was no evidence of one having been copied from the other." The committee's conclusion (on the entirety of the evidence which far exceeded that mentioned above) was that "The Committee finds that Dr. Lam's questionnaire was not copied from the Koo questionnaire."

You are wrong in stating that the committee "received written opinions on the similarity of Koo and Lam's questionnaires from 26 eminent epidemiologists": every single one said they were dissimilar.

The committee then examined the evidence of these distinguished scientists on the question whether instruments such as questionnaires (whatever the legal position) were in academic circles known to (or should), then or today, attract copyright or confidentiality after publication of the results derived from their use. (Koo had made her first public presentation of her results before Lam began to design his questionnaire, and had voluntarily given him her paper before publication.) This question was relevant to whether, if Lam had made use of parts of Koo's questionnaire (which they emphatically concluded he had not) such use would have been "disgraceful or dishonourable" conduct for disciplinary purposes.

The committee pointed out that:
"The reasons given for the free (i.e. uncopyrighted) use of questionnaires are to do with the nature of the scientific enterprise. Knowledge is cumulative, building on past efforts. The spirit and practice of free exchange of ideas increases progress in scientific discovery and knowledge. Feedback from colleagues, which plays an important role in clarifying one's ideas and in the development of research, becomes difficult in the absence of such exchanges. It is crucial, in order to test the validity of claims of discovery, that the methods of research undertaken by the person who claims to have-made that discovery be replicated in different contexts. Verification and falsification, which are essential methods for validation and progress, require the free use of questionnaires and other methods of research. It was pointed out to us that free exchange was particularly important in medical research since the whole aim of such research is to promote the well being of the community."

The legal decision of $\mathrm{Mr}$ Justice Bokhary and the court of appeal establishes for better or for worse, unless and until some higher court pronounces otherwise, that instruments such as questionnaires are capable of attracting copyright and confidentiality, so that they may be used or ideas taken from them in effect only with the express permission of the author. But what, I ask, is the effect of this on the research process, as well as on validation of research? Does the scientific community accept that this should be so? And if not, what can or should be done? John Griffiths

Des Voeux Chambers,

10/FBank of East Asia Building, 10 Des Voeux Road Central, Hong Kong

SIR - Plagiarism, although universally condemned, is only occasionally punished, and perhaps the most recent supposed example shows why. Here and there a degree has been withdrawn or a resignation forced because of frank copying of the results of someone else's scholarly labours.

That is not the case with Dr Lam, so your harsh comments about him and the university are unjustified. If he deliberately copied anything at all, it was not the results of an investigation but certain of the tools (somewhat like Watson and Crick copying from Franklin and Wilkins?). How far must one go, exactly, in acknowledging the primacy of others when designing a questionnaire?

The university, investigating a matter of great weight for the career of a member of staff, was not compelled to adhere to the findings of a civil court on another question, decided on a balance of probabilities and on different facts.

\section{T.R. C. Boyde}

123 Gloucester Place,

London W1H $3 P$ J, UK 